\title{
WAVECALC: An Excel-VBA spreadsheet to model the characteristics of fully developed waves and their influence on bottom sediments in different water depths
}

\author{
J.P. Le Roux ${ }^{\mathrm{a}}$, Z. Demirbilek ${ }^{\mathrm{b}}$, M. Brodalka ${ }^{\mathrm{c}}$, B.W. Flemming ${ }^{\mathrm{d}}$ \\ ${ }^{a}$ Departamento de Geología, Facultad de Ciencias Físicas y Matemáticas, Universidad de \\ Chile, Casilla 13518,Correo 21, Santiago,Chile.E-mail:jroux@cec.uchile.cl \\ ${ }^{\mathrm{b}}$ U.S. Army Engineer R\&D Centre, Coastal and Hydraulics Laboratory, Vicksburg, MS \\ 31980 \\ ${ }^{\mathrm{c}}$ University of Pretoria, Pretoria, South Africa \\ ${ }^{\mathrm{d}}$ Senckenberg Institute, Department of Marine Science, Suedstrand 40, 26382 \\ Wilhelmshaven, Germany
}

\begin{abstract}
The generation and growth of waves in deep water is controlled by winds blowing over the sea surface. In fully developed sea states, where winds and waves are in equilibrium, wave parameters may be calculated directly from the wind velocity. We provide an Excel spreadsheet to compute the wave period, length, height and celerity, as well as horizontal and vertical particle velocities for any water depth, bottom slope and distance below the reference water level. The wave profile and propagation can also be visualized for any water depth, modeling the sea surface change from sinusoidal to trochoidal and finally cnoidal profiles into shallow water. Bedload entrainment is estimated under the wave crest and trough, respectively, using the horizontal water particle velocity at the top of the boundary layer.

The calculations are programmed in an Excel file called WAVECALC, which is available online to authorized users. Although many of the recently published formulas are based on theoretical arguments, the values agree well with several existing theories and limited field and laboratory observations. WAVECALC is a user-friendly program intended for sedimentologists, coastal
\end{abstract}


engineers and oceanographers, as well as marine ecologists and biologists. It provides a rapid means to calculate many wave characteristics required in coastal and shallow marine studies and can also serve as an educational tool.

\section{Introduction}

When winds blow over the ocean surface for a sufficiently long distance (fetch) and duration, waves grow until they reach a maximum height and length for the specific conditions, from which point the wave period remains constant even as they propagate into shallow water. For such fully developed (Airy) waves, the wave celerity closely approximates the wind velocity, which, in the present context, is considered to remain constant at any distance above the still water level (Le Roux, 2008a). Under such equilibrium conditions, all the deepwater wave characteristics can be estimated from the wind velocity alone. This is also the case when fully developed waves shoal over a very gently rising bottom.

Here we present an Excel spreadsheet (WAVECALC) to compute the characteristics of Airy waves propagating into shallow water up to the breaking depth, including deformation of the wave profile due to the effects of shoaling. However, refraction, reflection, or wave-current and wave-wave interactions are not considered.

To characterize fully developed waves from deep water up to breaking depth, the only input required is the wind velocity and sea floor slope, although the program also provides for the input of directly measured parameters. The computations allow the horizontal particle velocity at the top of the boundary layer to be determined, so that bedload entrainment can be predicted under the wave crest and trough in any water depth.

The program should be viewed as an easy-to-use tool for studies in a variety of disciplines including ocean and coastal engineering, marine geoscience, biology and ecology, as well as having educational value. An advantage of using Excel is that it is widely available and easily adaptable to individual needs, in comparison with, e.g., Dalrymple's Coastal Engineering Page (http://www.oce.uri.edu/ grilli/APLET/index_appl.html), where users cannot access the equations.

It must be emphasized that the program is only valid for fully developed waves with deepwater Airy characteristics, because developing waves have different parameters (Le Roux, 2009). 


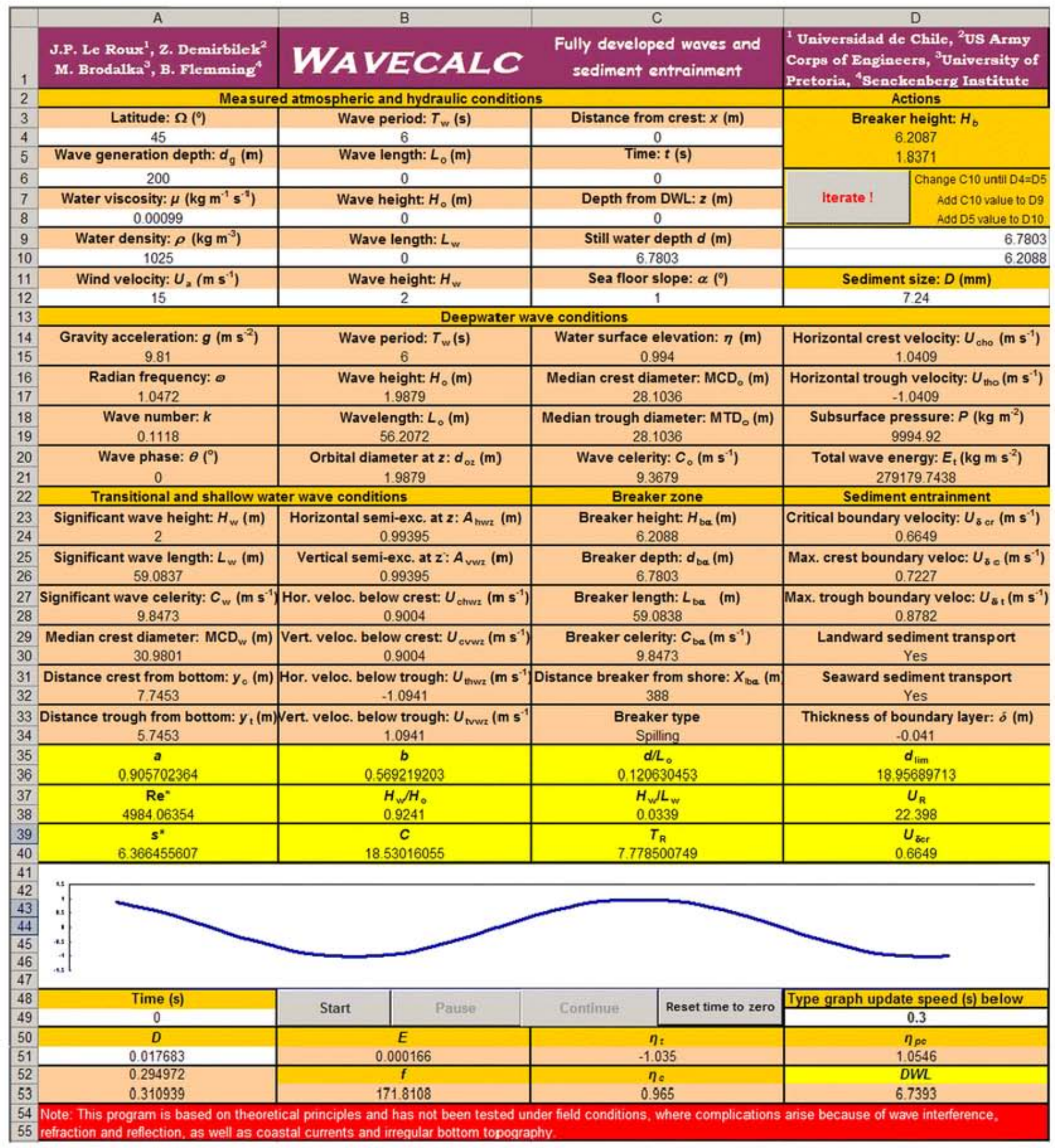

Fig. 1 Screenshot of the WAVECALC spreadsheet showing the layout of input and output areas for a wave period of $6 \mathrm{~s}$ and a wave height of $2 \mathrm{~m}(t o p)$. The graph at the bottom illustrates the corresponding shape of the wave 
Furthermore, although the equations presented here are internally coherent and correspond well to existing theories (e.g. Airy, 1845; Stokes, 1847; 1880; Boussinesq, 1871; Korteweg and De Vries, 1895; Dean, 1965; Cokelet, 1977; Miles, 1980; Sakkai and Battjes, 1980; Fenton, 1985; 1988; Fenton and McKee, 1990) and published laboratory observations (e.g. Shore Protection Manual, 1984; Dean and Dalrymple, 1991), they have not yet been tested rigorously under field conditions, where complications may arise because of wave interference, different types of marine currents, wave reflection and refraction, as well as irregular bottom topography.

Our goal is to describe the key elements of the WAVECALC program and to provide guidance on its application. The theoretical arguments behind the equations are discussed in detail in the original paper from which they are taken, and are only briefly summarized in the following section. The WAVECALC.xls Excel file is supplied in the electronic supplementary material available online to authorized users.

\section{Theoretical and empirical basis of equations used in the program}

Although equations are treated in the next section in the same order as they appear in the spreadsheet, most of the calculations are based on four elements: the wavelength $L_{o}$ (where the subscript ${ }_{o}$ indicates fully developed deepwater conditions), the wave height $H_{o}$, the breaker depth $d_{b}$ (conditions at breaking being indicated by the subscript ${ }_{b}$ ), and the breaker height $H_{b}$.

The deepwater wavelength is given by standard Airy (1845) theory (Eq. (8)), whereas the wave height (Eq. (7); Le Roux, 2007a) is based on the Joint North Sea Wave Project (JONSWAP) growth law for peak frequency, an equation for the fully developed frequency, and the assumption that a local wave field propagates at a group velocity equal to 0.85 times the group velocity of the spectral peak (Demirbilek et al., 1993; Resio et al., 2003).

Fully developed deepwater waves undergo various changes as they approach the shoreline. First, the wave height diminishes and then increases to reach a maximum just before breaking, the wavelength decreases, the horizontal water particle velocity in the wave crest increases, the wave shape changes from a sinusoidal to trochoidal and cnoidal profile, and the mean water level rises with respect to the still water level $(S W L)$. 
These changes are modeled here working backward from the breaker depth and height, which are found by simultaneously iterating the water depth $d$ in Eqs. (16) and (34) until the wave heights coincide. Eq. (16) is a theoretical shoaling model based on the $110^{\text {th }}$ order wave theory of Cokelet (1977), simplified into a 3-D graph by Sakkai and Battjes (1980), and recast into a single equation by Le Roux (2007a). It models the shoaling coefficient $\frac{H_{w}}{H_{o}}$ (where the subscript ${ }_{w}$ indicates any water depth) as a function of $\frac{H_{o}}{L_{o}}$ and $\frac{d}{L_{o}}$, so that it can be used to find $H_{w}$ for any combination of $H_{o}, L_{o}$ and $d$. Eq. (34) is based on experimental data on the breaking depth as a function of the bottom slope angle $\alpha$ (Shore Protection Manual, 1984). Le Roux (2007a) showed that the combination of Eqs. (16) and (34) coincides almost exactly with the well-known equation of Miche (1944) over a nearly horizontal bottom and also conforms to laboratory measurements (Dean and Dalrymple, 1991).

The breaker depth and height are used to calculate the breaker length $L_{b}$, based on the premise that the breaker celerity must be equal to the surf bore velocity just after breaking and that the surf bore behaves as a solitary wave (Le Roux, 2007b). Eq. (35), derived from this assumption, uses half the breaker height, which was subsequently pointed out by Hedges (2009) as having been widely applied in an empirical modification of a related Airy expression over the last 30 years (Kirby and Dalrymple, 1986; Dingemans, 1997; Wang et al., 2002; Bell et al., 2004) and agreeing well with large-scale laboratory experiments (Catalán and Haller, 2008). Le Roux (2007b) also compared the obtained breaker lengths with those calculated from cnoidal theory (Boussinesq, 1871; Korteweg and De Vries, 1895) and found that they agree to within $4.5 \%$.

The breaker length $L_{b}$ can be used to calculate the wavelength in any water depth $L_{w}$ according to Eq. (21). Working back from the breaker depth to the depth at which the wavelength reaches its deepwater value, Le Roux (2007b) demonstrated that this coincides with graphs in Dean and Dalrymple (1991) and Demirbilek and Vincent (2002).

Using the wavelength $L_{w}$, the median crest diameter $\left(M C D_{w}\right)$ can be found from Eq. (23). This was shown by Le Roux (2008a) to be in accordance with cnoidal theory, as graphically simplified by Wiegel (1960). The $M C D_{w}$ varies from $\frac{L_{o}}{2}$ in deep water to $\frac{L_{o}}{6}$ at breaking depth, and is used to calculate the horizontal water particle semi-excursion $\left(A_{h w z}\right)$ and velocity under the wave crest $\left(U_{c h w z}\right)$ in any water depth and at any distance $z$ from the $S W L$ (Eqs. (27) and (29)). In deep water, Eq. (27) 
yields the same value as that of the standard Airy equation $A_{h w z}=-\frac{H_{o}}{2} e^{\frac{2 \pi z}{L}}$, which inserted into Eq. (29) also yields values conforming exactly to those of the Airy equations $U_{c h w}=\frac{\pi H_{o}}{T_{w}}$ and $U_{c h w z}=\frac{\pi H_{o}}{T_{w}} e^{\left(\frac{2 \pi z}{L_{w}}\right)}$. Furthermore, at breaking Eq. (29) equals the wave celerity $C_{b}=\frac{L_{b}}{T_{w}}$, as it should (Stokes, 1880; Miles, 1980).

The horizontal water particle semi-excursion and velocity below the surface is calculated with reference to the displaced water level $(D W L)$. In deep water, the $S W L$ and $D W L$ coincide, but the latter rises with respect to the $S W L$ as the wave shoals, which is modeled by Eqs. (25) and (48) - (50). Le Roux (2008b) demonstrated that these equations exactly reproduce the wave shape given by the standard Airy equation $\eta(x)=\frac{H_{o}}{2} \cos \frac{2 \pi x}{L_{o}}$ (radians) in deep water, but also change the wave profile from sinusoidal to trochoidal and cnoidal into shallow water, in accordance with cnoidal theory and field observations. Eq. (55) models the elevation of the wave trough with respect to the $S W L\left(\eta_{t}\right)$ and coincides to within $3.5 \%$ with cnoidal theory (Le Roux, 2008b). The $D W L$ is therefore calculated by $D W L=\frac{H_{o}}{2}+\eta_{t}, H_{o}$ being used instead of $H_{w}$ because the latter initially diminishes with respect to its deepwater value before rising up to the breaker height. This would cause the $D W L$ to decrease, which is not the case. Furthermore, if $H_{w}$ were to be used in Eq. (28), the calculated vertical water particle semi-excursion would not always be zero at the sea floor in deep and transitional depths where the mean water surface still coincides with the $S W L$, whereas the horizontal water particle velocity would not equal the wave celerity at breaking, as it should.

The vertical water particle semi-excursion and velocity under the wave crest (Eqs. (28) and (30)) also coincide with the standard Airy equations in deep water, given by $A_{v w z}=\frac{H_{o}}{2} e^{\frac{2 \pi z}{L}}$ and $U_{c v w z}=\frac{\pi H_{o}}{T_{w}} e^{\left(\frac{2 \pi z}{L_{w}}\right)}$, respectively. However, in shallow water where the $D W L$ begins to rise above the $S W L$, Eq. (28) models the vertical semi-excursion and velocity to reach zero at a distance of $z=d$ below the $D W L$ (where $d$ is always the $S W L$ depth). This is taken to represent the top of the boundary layer, which is subsequently used in the sediment entrainment equations. 
Eqs. (31) and (33) model the water particle velocity under the wave trough, yielding values considerably lower than under the wave crest in shallow water. This is because the wave troughs are much wider than the crests at these depths, which means that more time is available for the water particles to complete the half-circuit below the $D W L$ than above the latter (Le Roux, 2008a).

The equations for sediment entrainment are derived from experimental data on the critical boundary velocity under oscillatory waves (Bagnold, 1946; Manohar, 1955; Rance and Warren, 1969; Hammond and Collins, 1979; You and Yin, 2006; Le Roux, 2007c). The method is described in section 4.4 .

\section{Use of the spreadsheet: Data input area}

All input and output data in WAVECALC, except the sediment grain size, are in SI units. In the data input area (cells A2:D12), measured atmospheric and hydraulic conditions are entered, where available. The latitude $\Omega$ in cell A4 is required to compute $g$, the acceleration due to gravity, in cell A15, although the value in this cell may be kept as $45^{\circ}$ if it is preferred to keep $g$ constant at $9.81 \mathrm{~m} \mathrm{~s}^{-}$

2. The wave generation depth $\left(d_{g}\right)$ in cell A6 can also be left at $200 \mathrm{~m}$ (the average depth of the continental shelf), unless the waves are generated in shallow water, in which case both the deepwater height $\left(H_{o}\right)$ and period $\left(T_{w}\right)$ have limiting values determined by the actual depth. The latter should be supplied in such cases.

The dynamic water viscosity $(\mu)$ in cell A8 and density $(\rho)$ in cell A10 can be left at $0.00099 \mathrm{~kg}$ $\mathrm{m}^{-1} \mathrm{~s}^{-1}$ and $1025 \mathrm{~kg} \mathrm{~m}^{-3}$ for sea water, respectively, but if the salinity and temperature of the water are known, these values can be calculated more precisely and entered in the relevant cells.

When the sustained wind velocity ( $U_{a}$, measured at a distance of $10 \mathrm{~m}$ above the $S W L$ ) is supplied (cell A12), there is no need to know the wave period, length or height, because these parameters are calculated automatically in the data output area (cells B14-B19). The values of these parameters should therefore be left as zero in their respective cells (B3 - B8). However, if any of these parameters are actually recorded in the field, the entered values take preference over the calculated values and will override the latter in the data output area. The measured wavelength and height in any water depth can also be entered in cells B10 and B12, which similarly override the automatically calculated values in cells A26 and A24, respectively. 
In cells $\mathrm{C} 4$ and $\mathrm{C} 6$, the distance $(x)$ from the wave crest in the direction of wave propagation and the time lapse $(t)$ are entered to calculate the surface elevation $(\eta)$ in cell C15 with respect to the $S W L$ at a specific point or moment in time.

Cell C8 is designated for the distance $z$ below the $D W L$, defined as the distance of the trough from the bottom $y_{t}$ plus half the deepwater wave height $\frac{H_{o}}{2}$. This is indicated in cell D53. The horizontal and vertical particle velocities calculated in cells B28:B34 are with reference to the $D W L$.

In cell $\mathrm{C} 10$, the $S W L$ water depth $(d)$ for which the wave parameters are required, is entered. This affects only the values for transitional and shallow water conditions in cells A22 - C34, because the deep water conditions are calculated separately in cells A13 - D21.

The sea floor slope is entered (in degrees) in cell C8. This directly determines the breaker height $H_{b}$ and depth $d_{b}$ (cells C24 and C26) as well as the wavelength $L_{w}$ at any depth $d$.

Finally, the sediment median grain size $D$ is entered in cell $\mathrm{D} 12$, in $\mathrm{mm}$. The program uses this value, together with the dynamic water viscosity and density in cells A8 and A10, to calculate the critical water particle velocity above the boundary layer (hereafter referred to as the critical boundary layer velocity $U_{\delta c r}$ ). The calculation of sediment entrainment assumes a quartz density of $2650 \mathrm{~kg} \mathrm{~m}^{-3}$. The computation is done in cells A40:C40, with the final value appearing in cell D24.

\section{Data output area}

Equations for deepwater wave conditions

Cell A15 calculates the gravity constant $g$ in $\mathrm{m} \mathrm{s}^{-2}$ for different latitudes $(\Omega)$ using the standard equation

$$
g=\frac{978.049\left[1+5.2884 \times 10^{-3}(\sin \pi \Omega)^{2}\right]-5.9 \times 10^{-6}(\sin 2 \pi \Omega)^{2}-0.011}{100}
$$

The radian frequency $\omega$ in cell A17 is given by:

$$
\omega=\frac{2 \pi}{T_{w}}=\frac{g}{U_{a}}
$$

The wave number $k$ is calculated in cell A19: 
$k=\frac{2 \pi}{L_{o}}=\frac{4 \pi^{2}}{g T_{w}{ }^{2}}=\frac{g}{U_{a}{ }^{2}}$

The wave phase $\theta$ is indicated in cell A21:

$\theta=a b s\left[\frac{-360(k x-\omega t)}{2 \pi}\right]=a b s\left[\frac{-360\left(\frac{x g}{U_{a}{ }^{2}}-\frac{g t}{U_{a}}\right)}{2 \pi}\right]$

When $\omega$ and $k$ are zero, the wave phase is $0^{\circ}$.

The wave period is read either directly from cell B4 or determined from the wind velocity at 10-m height. Le Roux (2008a) showed that fully developed waves move at a celerity closely approaching the wind velocity. At this stage, the wind velocity at the $S W L$ is equal or very close to its velocity at a $10-\mathrm{m}$ height, so that the fully developed wave period $T_{w}$ can be obtained by:

$$
T_{w}=\frac{2 \pi U_{a}}{g}
$$

The values obtained for $T_{w}$ in this way correspond closely to those given by the ACES program of the U.S. Army Corps of Engineers (Leenknecht et al., 1992) for wind velocities between 2.5 and 20 $\mathrm{m} \mathrm{s}^{-1}$, thereafter giving somewhat lower values.

The maximum wave period is also dependent on the depth $d_{g}$ in which the waves are generated (Vincent, 1985), in that it cannot exceed

$$
T_{w}=9.78 \sqrt{\frac{d_{g}}{g}}
$$

The deepwater wave height in cell B17 is read directly from cell B8 or calculated using the equation of Le Roux (2007b):

$$
H_{o}=\frac{g T_{w}{ }^{2}}{18 \pi^{2}}=\frac{2 U_{a}{ }^{2}}{9 g}
$$

The maximum wave height is limited by $d_{g}$, not exceeding $0.6 d_{g}$ (Resio et al., 2003, p. II-2 47).

The deepwater wavelength $L_{o}$ in cell B19 is taken from cell B6 or computed using the standard Airy (1845) equation:

$$
L_{o}=\frac{g T_{w}^{2}}{2 \pi}=\frac{2 \pi U_{a}^{2}}{g}
$$


The orbital diameter $2 A_{z}$ of the water particle motion at any distance $z$ from the $S W L$ is given in cell B21, from Airy (1845) theory:

$$
2 A_{z}=H_{o} \exp \left(\frac{-2 \pi z}{L_{o}}\right)=\frac{2 U_{a}^{2}}{9 g} \exp \left(\frac{-g z}{U_{a}^{2}}\right)
$$

Because the value of $z$ is entered in cell $\mathrm{C} 8$ as a positive number, a minus sign is used in the numerator in Eq. (9), as well as other equations involving $z$.

In cell $\mathrm{C} 15$ the elevation of the water surface $(\eta)$ in relation to the $S W L$ is calculated as a function of the wave phase using the standard equation (in radians):

$$
\eta(x, t)=\frac{H_{o}}{2} \cos \left[\frac{2 \pi x}{L_{o}}-\frac{2 \pi t}{T_{w}}\right]=\frac{U_{a}^{2}}{9 g} \cos \left[\frac{g x}{U_{a}^{2}}-\frac{g t}{U_{a}}\right]
$$

where $x$ is the distance from the wave crest in the direction of wave propagation and $t$ is the time lapse.

In cells $\mathrm{C} 17$ and $\mathrm{C} 19$ the median deepwater crest $\left(M C D_{o}\right)$ and trough $\left(M T D_{o}\right)$ diameters, defined as the distance between the wave flanks under the crest and over the trough, respectively, at a level halfway between the crest and trough (Le Roux, 2008a) are calculated, both using the same equation:

$$
M C D_{o}=M T D_{o}=\frac{L_{o}}{2}=\frac{\pi U_{a}^{2}}{g}
$$

The deepwater wave celerity $C_{o}$ (cell C21) is obtained from the standard Airy (1845) equation:

$$
C_{o}=\frac{g T_{w}}{2 \pi}=U_{a}
$$

The deepwater horizontal water particle velocity (which is the same as the vertical particle velocity) in the wave crest $\left(U_{c h o z}\right)$ and trough $\left(U_{\text {thoz }}\right)$, respectively, is calculated for any distance $z$ from the $S W L$ by the standard equation (Airy, 1845) in cells D15 and D17 as

$$
U_{c h o z}=U_{t h o z}=\frac{\pi H_{o}}{T_{w}} \exp \frac{-2 \pi z}{L_{o}}=\frac{U_{a}}{9} \exp \frac{-g z}{U_{a}^{2}}
$$

where values are shown as positive for $U_{c h o z}$ and negative for $U_{t h o z}$.

The subsurface gauge pressure is calculated in cell D19 from

$$
P=\rho g \eta\left(\exp \frac{-2 \pi z}{L_{o}}\right)-\rho g z
$$


In cell $\mathrm{D} 21$, the total wave energy $E$ is found by

$$
E=\frac{\rho g H_{o}^{2} L_{o}}{8}
$$

Equations for transitional and shallow water conditions

After entering the wind velocity in cell A12, as well as adjusting the water viscosity and density as required in cells A8 and A10, transitional and shallow water wave conditions can be obtained for any water depth $(d)$ and bottom slope $(\alpha)$ by changing these respective values in cells $\mathrm{C} 10$ and $\mathrm{C} 12$. However, it is first necessary to calculate the breaker height and depth. This calculation requires iteration, which is done by first entering a value in cell C10 and then clicking on "Iterate!" in cell D6. If the initial value is too high, a message will appear that the values are diverging, upon which a lower value should be entered. The program automatically changes the value in D6 until the values in cells D4 and D5 coincide, after which this depth is entered in cell D9. The breaker height obtained in cell D5 is entered in cell D10. The values in cells D9 and D10 must be retained for any specific wave climate, but the depth in cell C10 may be changed subsequently to model wave conditions at different depths.

The significant wave height $H_{w}$ in any water depth $d$ in cell A24 is derived from a threedimensional graph of Sakai and Battjes (1980) as reproduced in Demirbilek and Vincent (2002). This graph plots the ratio $\frac{d}{L_{o}}$ against $\frac{H_{w}}{H_{o}}$ for various ratios of $\frac{H_{o}}{L_{o}}$. Recasting these plotted relationships into a single equation yields (Le Roux, 2007a):

$$
H_{w}=H_{o}\left[a \exp \left(\frac{H_{o}}{L_{o}} b\right)\right]=\frac{2 U_{a}^{2}}{9 g}\left[a \exp \left(\frac{1}{9 \pi} b\right)\right]
$$

where $a$ and $b$ are coefficients (cells A36 and B36) given by

$$
\begin{aligned}
& a=0.5875\left(\frac{d}{L_{o}}\right)^{-0.18} \text { when } \frac{d}{L_{o}} \leq 0.0844 \\
& a=0.9672\left(\frac{d}{L_{o}}\right)^{2}-0.5013 \frac{d}{L_{o}}+0.9521 \text { when } 0.0844<\frac{d}{L_{o}} \leq 0.6
\end{aligned}
$$




$$
\begin{aligned}
& a=1 \text { when } \frac{d}{L_{o}}>0.6 \\
& b=0.0042\left(\frac{d}{L_{o}}\right)^{-2.3211}
\end{aligned}
$$

To obtain the wavelength $L_{w}$ at any depth $d$ in cell A26, an equation proposed by Le Roux (2007b) is used:

$$
L_{w}=\sqrt{L_{b} T_{w}\left[g\left(0.5 H_{b}+d\right)\right]^{1 / 2}}
$$

where $L_{b}$ is the wavelength at breaking (see below). The limiting value of $d$ (cell D36), from which the wavelength at increasing depth corresponds to Airy (1845) theory, is $\frac{L_{o}}{2.965}$ (Le Roux, 2007b). Eq. (21) corresponds very well to cnoidal theory (Boussinesq, 1871; Korteweg and De Vries, 1895; Wiegel, 1960; Le Roux, 2007b).

In cell $\mathrm{A} 28$, the wave celerity at any depth $d$ is obtained by

$$
C_{w}=\frac{L_{w}}{T_{w}}
$$

The median crest diameter in any water depth $M C D_{w}$ is given in cell A30 by

$$
M C D_{w}=L_{w}-\frac{L_{o}}{2}
$$

because the median trough diameter remains constant from deep into shallow water over a nearly horizontal bottom (Le Roux, 2008a). Under these conditions, the horizontal water particle velocity in the breaker crest $U_{c h b}$ as calculated by Eq. (29) is exactly equal to the breaker celerity $C_{b}=\frac{L_{b}}{T_{w}}$, as it should (Stokes, 1880; Miles, 1980). Originally (Le Roux, 2008a), it was assumed that Eq. (23) would also be valid over sloping bottoms where the wave advances beyond the point of where it would have broken over a nearly horizontal bottom. Further analysis of this concept, however, shows that the difference between $U_{c h b}$ and $C_{b}$ becomes unrealistically large as the wave period and slope increase. For a $12 \mathrm{~s}$ wave $\left(H_{o}=7.9517 \mathrm{~m}\right.$; Eq. (7)) breaking over a $6^{\circ}$ slope, $d_{b}=8.9621 \mathrm{~m}$ and $H_{b}=10.8549 \mathrm{~m}$ (Eqs. (16) - (20) and (34)). $L_{b}$ in this case reduces to $142.5735 \mathrm{~m}$ (Eq. (35)), so that $C_{b}=$ $\frac{142.5735}{12}=11.8811 \mathrm{~m} \mathrm{~s}^{-1}$. The $M C D_{b}$ in this case would therefore be 
$142.5735-\left(\frac{224.8286}{2}\right)=30.1592 \mathrm{~m}$, giving a $U_{c h b}$ of $18.3408 \mathrm{~m} \mathrm{~s}^{-1}$ that greatly exceeds $C_{b}$.

Adjusting the water depth while calculating the various parameters shows that $U_{c h w}$ in fact already equals $C_{w}=12.4905 \mathrm{~m} \mathrm{~s}^{-1}$ at a depth of $12.1492 \mathrm{~m}$, which would be at a distance of $30 \mathrm{~m}$ from the actual breaker for this slope. Clearly, the wave cannot plunge over such a long distance, which indicates that $M C D_{w}$ cannot decrease at a ratio similar to that over a nearly horizontal bottom.

A solution to the problem stated above is found in Eq. (21). It transpires that, over a horizontal bottom, substituting $d$ with $d_{b}, \sqrt{g\left(0.5 H_{b}+d_{b}\right)}=\sqrt{9.81\left(\frac{9.368}{2}+11.2191\right)}=12.4904 \mathrm{~m} \mathrm{~s}^{-1}$ $\left(H_{b}=9.368 \mathrm{~m} ; d_{b}=11.2191 \mathrm{~m} ; L_{b}=149.8845 \mathrm{~m}\right)$, which is equal to both $U_{c h b}$ and $C_{b}$ and also dimensionally correct. Therefore, setting $\sqrt{g\left(0.5 H_{b}+d_{b}\right)}=\frac{g T_{w} H_{o} L_{w}}{8 M C D^{2}}$ yields $M C D_{w}=$ $\sqrt{\frac{g T_{w} H_{o} L_{w}}{8\left[g\left(0.5 H_{b}+d\right)\right]^{1 / 2}}}$. Using the values above for slopes of $0^{\circ}$ and $6^{\circ}$, respectively, it is found that $M C D_{b}=37.4715 \mathrm{~m}$ at breaking in both cases, in spite of the fact that $L_{b}, H_{b}$ and $d_{b}$ change simultaneously with the slope. $M C D_{w}$ should therefore remain constant from about the depth where it would have broken over a nearly horizontal bottom (there is a slight difference of $0.34 \mathrm{~m}$ in this case) to the actual breaking depth over a sloping bottom, thus reaching a minimum value at the former point. This value is given by $\frac{L_{o}}{6}$, i.e. equal to the $M C D_{b}$ over a horizontal bottom (Le Roux, 2008a). Keeping $M C D_{w}$ constant over any bottom slope results in $U_{c h b}$ always equaling $C_{b}$ shoreward of the horizontal bottom breaking depth, so that the horizontal water particle velocity in the wave crest actually decreases over sloping bottoms because $C_{b}$ decreases with the wavelength.

If the $M C D_{w}$ remains constant while the wavelength decreases beyond the horizontal bottom breaking depth, this also means that the median trough diameter $M T D_{w}$ would be given by $L_{w}-\frac{L_{o}}{6}$ shoreward of this point, thus decreasing in contrast to the $M C D_{w}$. This in turn means that the seaward horizontal water particle velocity in the wave trough increases over sloping bottoms beyond the horizontal bottom breaking depth. For example, over a $6^{\circ}$ bottom slope, $M T D_{b}=105.1021 \mathrm{~m}$ and 
$U_{t h b}=1.5102 \mathrm{~m} \mathrm{~s}^{-1}$, in contrast to a horizontal velocity of $1.3878 \mathrm{~m} \mathrm{~s}^{-1}$ at breaking over a nearly horizontal bottom.

In cells $\mathrm{A} 32$ and $\mathrm{A} 34$, the distance from the bottom to the wave crest $\left(y_{c}\right)$ and wave trough $\left(y_{t}\right)$ are computed, respectively. This is because the wave profile becomes asymmetrically distributed around the $S W L$ in shallow water. These distances can be calculated from the wave profile (Le Roux, 2008b). The distance of the wave trough from the bottom is computed in cell A34 by

$$
y_{t}=d+L_{w}\left(-0.017683+9.64 \times 10^{-7} f\right)
$$

where $f$ is found in cell B53 by

$$
f=\left[\frac{\left(2+\cosh \frac{4 \pi d}{L_{w}}\right)\left(\cosh \frac{2 \pi d}{L_{w}}\right)}{2\left(\sinh \frac{2 \pi d}{L_{w}}\right)^{3}}\right]^{3}
$$

The crest distance from the bottom is provided in cell A32 by

$$
y_{c}=y_{t}+H_{w}
$$

Le Roux (2008b) showed that Eq. (24) corresponds closely to cnoidal theory (Boussinesq, 1871; Wiegel, 1960; Demirbilek and Vincent, 2002).

Cells B24 and B26 are used to compute the horizontal and vertical semi-excursion or amplitude of water particle displacement under the wave crest at different distances below the $S W L$, using the equations of Le Roux (2008a). The horizontal semi-excursion under the crest $A_{h w z}$ is found in any water depth by

$$
A_{h w z}=\frac{H_{o}}{2}\left[\frac{\cosh \frac{\pi(d-z)}{M C D_{w}}}{\cosh \frac{\pi d}{M C D_{w}}}\right]
$$

and the vertical semi-excursion under the crest $A_{v w z}$ by

$$
A_{v w z}=\frac{H_{o}}{2}\left[\frac{\sinh \frac{\pi(d-z)}{M C D_{w}}}{\sinh \frac{\pi d}{M C D_{w}}}\right]
$$

It should be pointed out that Eqs. (27) and (28) are corrected versions of the original equations in Le Roux (2008a), where values of $2 \pi$ were erroneously used. 
Cells B27 - B34 are dedicated to the calculation of horizontal and vertical water particle velocities under the crest and trough at different distances from the $S W L$, based on the horizontal semi-excursions (Le Roux, 2008a). The horizontal velocity under the crest $U_{c h w z}$ is calculated for any water depth in cell B28:

$$
U_{c h w z}=\frac{A_{h w z} g T_{w} L_{w}}{4 M C D_{w}{ }^{2}}
$$

The vertical velocity under the crest $U_{c v w z}$ is found in cell B30 from

$$
U_{c v w z}=\frac{A_{v w z} g T_{w} L_{w}}{4 M C D_{w}{ }^{2}}
$$

Similarly, the horizontal velocity under the wave trough $U_{t h w z}$ at any distance $z$ from the $S W L$ in any water depth is derived in cell B32 from

$$
U_{t h w z}=\frac{A_{h w z} g T_{w} L_{w}}{4 M T D_{w}{ }^{2}}
$$

where $M T D_{\mathrm{w}}$ is given by

$$
M T D_{w}=L_{w}-M C D_{w}
$$

As shown above, $M T D_{w}$ decreases according to $L_{w}-\frac{L_{o}}{6}$ after $M C D_{w}$ had reached its minimum value of $\frac{L_{o}}{6}$.

The vertical water particle velocity $U_{t v w z}$ under the wave trough is found in cell B34 by

$$
U_{t v w z}=\frac{A_{v w z} g T_{w} L_{w}}{4 M T D_{w}{ }^{2}}
$$

Equations for conditions in the breaker zone

This area is dedicated to the breaker zone. The breaker height $H_{b}$ is calculated using an iterative procedure proposed by Le Roux (2007a). Tests of periodic waves with periods from $1-6 \mathrm{~s}$ on slopes $(\alpha)$ between 0 and $11.3^{\circ}$ were tabulated in the Shore Protection Manual (1984), yielding the relationship:

$$
H_{b}=d_{b}\left(-0.0036 \alpha^{2}+0.0843 \alpha+0.835\right)
$$


where $\alpha$ is the sea floor slope in degrees.

Eqs. (34) and (16) - (20) are calculated simultaneously by changing the water depth (the only variable that is not fixed for any specific wave climate) until the $H_{b}$ and $H_{w}$ values coincide. This yields both the breaker height $H_{b}$ (cell C24) and breaker depth $d_{b}$ (cell C26) and takes account of the $\frac{H_{o}}{L_{o}}$ ratio as well as the sea floor slope.

The wavelength just seaward of the breaker is computed in cell C28 using an equation proposed by Le Roux (2007b).

$$
L_{b \alpha}=T_{w} \sqrt{g\left(0.5 H_{b \alpha}+d_{b \alpha}\right)}
$$

Over a nearly horizontal bottom, this reduces to

$$
L_{b}=\frac{2 L_{o}}{3}=\frac{4 \pi U_{a}^{2}}{3 g}
$$

Eqs. (35) and (36) coincide closely with the cnoidal wavelength at breaker depth (Le Roux, 2007b).

In cell $\mathrm{C} 30$, the celerity of the breaker $C_{b \alpha}$ is calculated by $\frac{L_{b \alpha}}{T_{w}}$. Over a nearly horizontal bottom, it becomes

$$
C_{b}=\frac{2 U_{a}}{3}
$$

The distance of the breaker from the $S W L$ shoreline is calculated by

$$
X_{b \alpha}=\frac{d_{b \alpha}}{\tan \alpha}
$$

The type of breaker, i.e. spilling, plunging or collapsing, is shown in cell C34. This is based on a slope of less than $5.4^{\circ}, 5.4-31.8^{\circ}$ and more than $31.8^{\circ}$, respectively (Galvin, 1968; Battjes, 1974; Le Roux, 2008a). 
Equations for sediment entrainment

Predicting sediment transport under waves is notoriously difficult. Most methods are based on laboratory studies and linear wave theory (e.g. Bagnold, 1946; Manohar, 1955; Rance and Warren, 1969; Komar and Miller, 1973; Madsen and Grant, 1976; Migniot, 1977; Hammond and Collins, 1979; Rigler and Collins, 1983; White, 1989; Asano, 1990; Soulsby and Whitehouse, 1997; Dong and Zhang, 1999; Le Roux, 2001; Nielsen and Callaghan, 2003; Hassan and Ribberink, 2005; Wang, 2007) and are therefore not directly applicable to non-linear wave conditions in the field. The required horizontal semi-excursion $\left(A_{\delta}\right)$ or the orbital velocity at the top of the boundary layer $\left(U_{\delta}\right)$ can be measured in the laboratory, but has been impractical under field conditions because the thickness of the boundary layer was uncertain. Most published methods therefore determine only the critical and not the actual boundary velocity, and then rely on linear wave theory (e.g. the dispersion equation) to estimate conditions at the top of the boundary layer.

In the WAVECALC program, the determination of sediment entrainment is based on the method of Le Roux (2010), which compares the theoretically calculated maximum horizontal water particle velocity at the top of the boundary layer $\left(U_{\delta}\right)$ with the critical boundary velocity $U_{\delta c r}$ determined according to the method of You and Yin (2006), as modified by Le Roux (2007c). There is thus no need to physically measure the semi-excursion or orbital velocity as in previous methods, because these elements, together with the thickness of the boundary layer, can be determined theoretically for any water depth under both linear and non-linear wave conditions. However, no attempt was made here to calculate the actual bedload transport, because the critical boundary velocity is exceeded only for a short period during the wave cycle and is dissimilar under the wave crest and trough, respectively. This aspect will be addressed in future studies.

The critical boundary velocity $U_{\delta c r}$ for sediment entrainment, based on measurements under laboratory conditions, is determined in cell D24 as follows (You and Yin, 2006):

$$
U_{\delta c r}=2 \pi J\left[1+5\left(\frac{T_{R}}{T_{w}}\right)^{2}\right]^{-0.25}
$$

where $J$ and $T_{R}$ are coefficients derived from $s^{*}$, a scaled dimensionless immersed sediment weight given in cell A40 by 


$$
s^{*}=\frac{D \sqrt{g D\left(\rho_{s}-\rho\right)}}{4 v}
$$

$v$ being the kinematic viscosity $\left(\frac{\mu}{\rho}\right)$ and

$$
T_{R}=\frac{159 s^{*-1.3} D^{2}}{v}
$$

In Eqs. (39) - (41) all values are in grammes, centimetres and seconds. When $U_{\delta c r}$ exceeds 80 $\mathrm{cm} \mathrm{s}^{-1}$, it is first multiplied by 1.5 , after which 40 is subtracted to obtain the correct value (Le Roux, 2007c).

Eq. (39) yields the critical boundary velocity required to entrain sediments with a specific mean size and density in water of which the density and viscosity are known, under waves with a particular period. However, it does not take the water depth into account and therefore cannot be used on its own to determine sediment entrainment under field conditions, where the boundary layer thickness, horizontal water particle displacement and velocity vary as a function of water depth.

These variables can be calculated for different water depths using the following equations (Le Roux, 2010): The value of $\delta$ is given in cell D34 by

$$
\delta=\frac{H_{o}}{2}+\eta_{t}
$$

where the distance of the wave trough below the $S W L\left(\eta_{t}\right)$ is found by

$$
\eta_{t}=L_{w}\left(-0.017683+9.64 \times 10^{-7} f\right)
$$

The actual boundary layer velocity under the wave crest $U_{\delta c}$ is calculated for any specific water depth in cell D26 by

$$
U_{\delta c}=\frac{H_{o} g T_{w} L_{w}}{8 M C D_{w}{ }^{2} \cosh \frac{\pi d}{M C D_{w}}}
$$

and under the wave trough (cell D28) by

$$
U_{\delta t}=\frac{H_{o} g T_{w} L_{w}}{8 M T D_{w}{ }^{2} \cosh \frac{\pi d}{M C D_{w}}}
$$

To take the bottom slope into account, a slope-adjusted critical boundary velocity $U_{\delta c r a}$ is obtained by 


$$
U_{\delta c r \alpha}=1.3934 U_{\delta c r} \sqrt{\sin (\phi+\alpha)}
$$

where $\varphi$ is the grain pivot angle, which is $31^{\circ}$ for well sorted, natural sediments as determined from experimental data (Whitehouse and Hardisty, 1988; Le Roux, 2005; Le Roux, 2010). The slope $\alpha$ is positive for landward and negative for seaward transport. This factor is taken into account in cells D30 and D32, which compare the critical boundary velocity required to entrain the sediments to the calculated boundary velocity under the wave crest and trough, respectively. If the critical boundary velocity is exceeded by the actual values, landward or seaward entrainment is indicated in these cells. By varying the water depth in cell $\mathrm{C} 10$, the depth at which the sediments first experience entrainment by wave action can thus be found.

\section{Additional information}

Cells A35 - D40 are used to calculate factors or coefficients required in the main program, but also include additional information such as the Ursell (1953) number (cell D38) given by

$$
U_{R}=\frac{L_{w}^{2} H_{w}}{d^{3}}
$$

The Ursell number, for example, can be used together with the wave steepness $\frac{H_{w}}{L_{w}}$ (cell C38)

to determine whether Airy, Stokes, cnoidal or solitary theory applies. According to Hedges (1995), Airy theory is applicable where $U_{R}<40$ and $\frac{H_{w}}{L_{w}}<0.04$; Stokes theory where $U_{R}<40$ and $\frac{H_{w}}{L_{w}} \geq$ 0.04; and cnoidal theory where $U_{R}$ reaches about 4000 . In the present case the equations model the waves as having a typical Airy shape where $U_{R}<5$, gradually assuming a trochoidal (Stokes) shape between $5<U_{R}<125$, and a cnoidal shape between $125<U_{R}<150$, approximately. Fully developed waves break when the $U_{R}$ reaches about 150 over a nearly horizontal bottom, but this increases with the bottom slope. 


\section{Wave profile and propagation}

The wave profile and propagation in any water depth is shown as a graph in cells A41 - D47. Clicking on "Start" shows the wave propagation with time $t$, which can be adjusted in cell D49 to speed up or slow down the propagation. This is intended mainly for educational purposes. The "Pause", "Continue" and "Reset" buttons have obvious functions.

The wave profile is calculated following Le Roux (2008b). First, a basic wave profile is computed with the equation (using radians)

$$
\eta_{p}(x)=L_{w}\left[G \cos \left(\frac{2 \pi x}{L_{w}}\right)+I \cos \left(\frac{4 \pi x}{L_{w}}\right)\right]
$$

In Equation (48), the subscript ${ }_{p}$ is used with $\eta$ to indicate that the water surface elevation is preliminary, i.e. that it requires a correction with regard to the wave height. $G$ has a fixed value of 0.017683 in any water depth for any fully developed wave, whereas $I$ is obtained from

$$
I=\pi^{2} G^{4} f
$$

where $f$ is found by Eq. (25). The value of $f$ is equal to 1 in deep water, but increases to about 4,621 at breaking depth over a nearly horizontal bottom.

In plotting the wave profile (cells G1 - L40), the total wavelength is divided by 24 , which is used as the increment distance $x_{\mathrm{i}}$ from the initial wave crest where $x=0$. The preliminary water elevation $\eta_{p}$ at each of these 24 points is first calculated from Eq. (48), which is then corrected at the wave crest where $x=0$ by adding $H_{w}$ to $\eta_{t}$, and at 4 locations on each side of the latter. The corrections at increasing increment distances of $L_{w} / 24$ from $x=0$ are calculated by

$$
\eta=\frac{\eta_{p}}{\left(\frac{\eta_{p c}}{\eta_{c}}\right)^{h}}
$$

where $\eta_{p c}$ is the provisional crest height as given by Eq. (48) and $\eta_{c}$ the corrected crest height. It should be pointed out that Eq. (50) was incorrectly published in Le Roux (2008b), where the numerator was shown to be multiplied instead of divided by the denominator. The value of the exponent $h$ is $0.8,0.6,0.455$, and 0.2 at an increasing distance from the crest, respectively. The ratio 
$\frac{\eta_{p c}}{\eta_{c}}$ is 1 in deep water so that $\eta=\eta_{p}$, ensuring that the crest shape returns to normal for deepwater conditions.

Because Eq. (48) is not a time series for shallow water waves, wave propagation is simulated by mathematical means.

\section{A practical example}

As an example of how the program can be used for educational purposes and preliminary engineering studies, consider a $15 \mathrm{~m} \mathrm{~s}^{-1}$ wind velocity and fully developed waves shoaling over a bottom slope of 1 degree. We want to determine the fully developed wave period $\left(T_{w}\right)$, deepwater height $\left(H_{o}\right)$ and length $\left(L_{o}\right)$, as well as the breaker height $\left(H_{b a}\right)$ and depth $\left(d_{b a}\right)$ and its distance from the shore $\left(X_{b a}\right)$. Furthermore, we need to know the depth at which well-sorted sand with a median size of $0.5 \mathrm{~mm}$ would commence to be transported land- and seaward, respectively, as well as the coarsest sediments that can be entrained under these conditions. After entering the required input values in cells A12, C12 and D12, a value of 1 is entered in cell $\mathrm{C} 10$ and the iteration process is started. This indicates a fully developed wave period of $9.61 \mathrm{~s}$ and a deepwater height and length of 5.1 and $144.11 \mathrm{~m}$, respectively. The waves will break $388 \mathrm{~m}$ from the shore at a depth of $6.78 \mathrm{~m}$, with a breaker height of $6.21 \mathrm{~m}$ and length of $94.61 \mathrm{~m}$. At this point there will be both land- and seaward transport of $0.5 \mathrm{~mm}$ sediment. Increasing the water depth in cell C10 gradually, it is found that seaward transport of this size fraction will take place up to a depth of about $54.76 \mathrm{~m}$, whereas landward transport of the same fraction will proceed from a depth of around $54.08 \mathrm{~m}$, the difference arising from the seaward slope. Under the breaker zone, the coarsest sediment that can be transported seaward is $7.24 \mathrm{~mm}$, compared to pebbles of at least $25 \mathrm{~mm}$ (the coarsest material that the program allows for, based on the tested limits of Eqs. (39) - (41) that can be transported shoreward.

For the same example, Dalrymple's Coastal Engineering Page returns the same deepwater wavelength of $144.21 \mathrm{~m}$. The breaking depth is indicated as $6.61 \mathrm{~m}$ (a difference of $2.5 \%$ with the value given by Eqs. (16) - (20) and (34)), at which point the breaker height and length are calculated at 5.29 and $73.66 \mathrm{~m}$, respectively. It should be noted that the breaker height is limited to a value of $0.8 d_{\mathrm{b}}$ by this program, whereas experimental work (Shore Protection Manual, 1984) indicates that the 
coefficient can actually increase to $1.32 d_{b}$ over bottom slopes of up to about $12^{\circ}$. The wavelength of $73.66 \mathrm{~m}$ underestimates the value of $94.61 \mathrm{~m}$ given by Eq. (35), but the latter corresponds better to cnoidal and stream function theories (Le Roux, 2007b). Using the breaker height of $6.21 \mathrm{~m}$ and wave period of $9.61 \mathrm{~s}$, together with the breaking depth of $6.78 \mathrm{~m}$ in the stream function wave theory $\left(10^{\text {th }}\right.$ order) of Dean (1965), together with a damping factor of 0.1 applicable to very non-linear waves (Dalrymple's Coastal Engineering Page), the wavelength is calculated at $94.01 \mathrm{~m}$, a difference of $0.5 \%$ with Eq. (35). However, the horizontal water particle velocity in the wave crest is given as 8.17 $\mathrm{m} \mathrm{s}^{-1}$ by the stream function theory, which is less than the breaker celerity of 9.85 given by $\frac{L_{b \alpha}}{T_{w}}$. According to Stokes (1880) and Miles (1980) waves can only break when the water particle velocity begins to exceed the wave celerity, so that the two should actually be equal at breaking depth. In this case WAVECALC computes $M C D_{b \alpha}$ as $\frac{L_{o}}{6}=24.02 \mathrm{~m}$ and $U_{c h b}=9.85 \mathrm{~m} \mathrm{~s}^{-1}$ according to Eq. (29), which is equal to $C_{b \alpha}=\frac{94.61}{9.61}=9.85 \mathrm{~m} \mathrm{~s}^{-1}$, as it should. In the wave trough, $M T D_{b \alpha}=L_{b \alpha}-24.02=$ $70.59 \mathrm{~m}$ and $U_{t h b}=1.140 \mathrm{~m} \mathrm{~s}^{-1}$, compared to $1.00 \mathrm{~m} \mathrm{~s}^{-1}$ given by the stream function theory.

\section{Concluding remarks}

The main advantage of the WAVECALC program is that it represents a set of simple, fully integrated equations applicable to all water depths, whereas different, much more complex theories had to be used previously for different depth zones. These different theories do not always give a seamless transition from deep to shallow water, as illustrated in the example above.

About $60 \%$ of the equations used in WAVECALC are standard and have been widely used in engineering or oceanographic studies over many decades, whereas the rest were only published during the last three years and have not yet been tested under field or laboratory conditions. Nevertheless, although the same basic equations are used for all water depths, they appear to correspond well to most of the major theories (Airy, 1845; Boussinesq, 1871; Stokes, 1880; Cokelet, 1977; Dean, 1965; Fenton, 1985; 1988; Fenton and McKee, 1990) within their applicable depth zones. 
Acknowledgements JPLR gratefully acknowledges the financial and logistical support of the Hanse Institute for Advanced Study in Delmenhorst, Germany, where this study was initiated during 2006. This research was supported by the Navigation System program, U.S. Army Engineer R\&D Center (for ZD). Permission was granted by Headquarters, U.S. Army Corps of Engineers, to publish this information. Several anonymous reviewers of previous versions are thanked for their valuable input.

\section{References}

Airy GB (1845) Tides and Waves. Encyclop Metrop Article 192: 241-396.

Asano T (1990) Two-phase model on oscillatory sheet flow. Proc. $22^{\text {nd }}$ Int Conf Coastal Eng, Delft pp 2372-2384.

Bagnold RA (1946) Motion of waves in shallow water. Interaction of waves and sand bottoms. Proc Royal Soc Ser A 187: 1-15.

Battjes JA (1974) Set-up due to irregular waves. Proc $14^{\text {th }}$ Coastal Eng Conf, ASCE, pp 1993-2004.

Bell PS, Williams JJ, Clark S, Morris BD, Vila-Concejo A (2004) Nested radar systems for remote coastal observations. Proc $8^{\text {th }}$ Int Coastal Symp (ICS) 2004. J Coastal Res, Special Issue 39.

Boussinesq J (1871) Theorie de l'intumescence liquide appelee onde solitaire ou de translation se propageant dans un canal rectangulaire. Comptes Rendus Acad Sci Paris 72: 755-759.

Catalán, PA, Haller MC (2008) Remote sensing of breaking wave phase speeds with application to non-linear depth inversions. Coastal Eng 55: 93-111.

Cokelet ED (1977) Steep gravity waves in water of arbitrary uniform depth. Phil Trans Roy Soc London, Ser A 286: 183-230.

Dean RG (1965) Stream function representation of nonlinear ocean waves. J Geophys Res 70: 45614572.

Dean RG, Dalrymple RA (1991) Water Wave Mechanics for Engineers and Scientists. World Scientific Pub Co, Teaneck, NJ.

Demirbilek Z, Bratos SM, Thomson EF (1993) Wind products for use in coastal wave and surge models. Misc Paper CERC-93-7, US Army Engr Waterways Exp Station, Vicksburg, MS.

Demirbilek Z, Vincent CL (2002) Water Wave Mechanics, Chapter II-1, Coastal Engineering Manual (EM 1110-2-1100). US Army Corps of Engrs, Washington DC, 121 pp. 
Dingemans MW (1997) Water wave propagation over uneven bottoms. World Scientific, Singapore.

Dong P, Zhang K (1999) Two-phase flow modeling of sediment motions in oscillatory sheet flow. Coastal Eng 36: 87-109.

Fenton JD (1985) A fifth-order Stokes theory for steady waves. ASCE J Waterw, Port, Coastal and Ocean Eng 111: 216-234.

Fenton JD (1988) The numerical solution of steady water wave problem. J Comp and Geo 14: 357368.

Fenton JD, McKee WD (1990) On calculating the lengths of water waves. Coastal Eng 14: 499-513.

Galvin CJ (1968) Breaker type classification on three laboratory beaches. J Geophys Res 73: 36513659.

Hammond, TM, Collins MB (1979) On the threshold of transport of sand-sized sediment under the combined influence of unidirectional and oscillatory flow. Sedimentology 26: 795-812.

Hassan WN, Ribberink JS (2005) Transport processes of uniform and mixed sands in oscillatory sheet flow. Coastal Eng 52: 745-770.

Hedges TS (1995) Regions of validity of analytical wave theories. Water, Maritime and Energy J Proc Inst Civ Engrs 61: 575-579.

Hedges TS (2009) Discussion of "A function to determine wavelength from deep into shallow water based on the length of the cnoidal wave at breaking" by JP Le Roux. Coastal Eng 56: 94-95.

Kirby JT, Dalrymple RA (1986) An approximate model for nonlinear dispersion in monochromatic wave propagation models. Coastal Eng 9: 545-561.

Komar PD, Miller MC (1973) Sediment threshold under oscillatory waves. J Sedim Petrol 43: 11011110.

Korteweg DJ, De Vries, G (1895) On the change in form of long waves advancing in a rectangular channel, and on a new type of stationary waves. Phil Mag $5^{\text {th }}$ Series 39: 422-443.

Leenknecht DA, Szuwalski A, Sherlock AR (1992) Automated Coastal Engineering System, User Guide and Technical Reference, Version 1.07. Coastal Engineering Research Center, US Army Engr Waterway Exp Station, Vicksburg, MS.

Le Roux JP (2001) A simple method to predict the threshold of particle transport under oscillatory waves. Sedim Geol 143: 59-70.

Le Roux JP (2005) Grains in motion: A review. Sedim Geol 178: 285-313. 
Le Roux JP (2007a) A simple method to determine breaker height and depth for different deepwater height/length ratios and sea floor slopes. Coastal Eng 54: 271-277.

Le Roux JP (2007b) A function to determine wavelength from deep into shallow water based on the length of the cnoidal wave at breaking. Coastal Eng 54: 770-774.

Le Roux JP (2007c) A unified criterion for initiation of sediment motion and inception of sheet flow under water waves - Discussion. Sedimentology 54: 1447-1448.

Le Roux JP (2008a) An extension of the Airy theory for linear waves into shallow water. Coastal Eng 55: $295-301$.

Le Roux JP (2008b) Profiles of fully developed (Airy) waves in different water depths. Coastal Eng 55: 701-703.

Le Roux JP (2009) Characteristics of developing waves a function of atmospheric conditions, water properties, fetch and duration. Coastal Eng 56: 479-483.

Le Roux JP (2010) Sediment entrainment under fully developed waves as a function of water depth, boundary layer thickness, bottom slope and roughness. Sedim Geol 223: 143-149.

Madsen OS, Grant WD (1976) Sediment transport in the coastal environment. MIT Ralph M Parson Laboratory Rep 209.

Manohar M (1955) Mechanics of bottom sediment movement due to wave action. Beach Erosion Board, Tech Memo, 75 pp.

Miche R (1944) Mouvements ondulatoires des mers en profondeur constante on decroisante. Annales des Ponts et Chaussees, pp 25-78, 131-164,270-292, 369-406.

Migniot C (1977) Action des courants, de la houle et du vent sur les sediments. La Houille Blanche 1/1977: 9-47.

Miles JW (1980) Solitary waves. Annual Rev Fluid Mech 12: 11-43.

Nielsen P, Callaghan DP (2003) Shear stress and sediment transport calculations for sheet flow under waves. Coastal Eng 47: 347-354.

Rance PJ, Warren NF (1969) The threshold of movement of coarse material in oscillatory flow. In: Proc $11^{\text {th }}$ Coastal Eng Conf, ASCE, New York, pp 487-491.

Resio, D.T., Bratos, S.M., Thompson, E.F., 2003. Meteorology and Wave Climate, Chapter II-2, Coastal Engineering Manual. US Army Corps of Engrs., Washington D.C., 72 pp. 
Rigler JK, Collins MB (1983) Initial grain motion under oscillatory flow: A comparison of some threshold criteria. Geo-Marine Lett 3: 43-48.

Sakai T, Battjes JA (1980) Wave theory calculated from Cokelet's theory. Coastal Eng 4: 65-84.

Shore Protection Manual, 1984. $4^{\text {th }}$ Ed., 2 Vol US Army Engineer Waterways Experiment Station. US Government Printing Office, Washington, DC.

Soulsby RL, Whitehouse RJS (1997) Threshold of sediment motion in coastal environments. In: Pacific Coasts and Ports 1997. 13 ${ }^{\text {th }}$ Australasian Coastal and Eng Conf and $6^{\text {th }}$ Australian Port and Harbour Conf, Christchurch, New Zealand. HR Wallington, Oxon, pp 149-154.

Stokes GG (1847) On the theory of oscillatory waves. Trans Camb Phil Soc 8: 441-455.

Stokes GG (1880) Math Phys Papers Vol 1, Cambridge Univ Press.

Ursell F (1953) The long wave paradox in the theory of gravity waves. Proc Cambridge Philos Soc 49: 685-694.

Vincent CL (1985) Depth-controlled wave height. ASCE J Waterway, Port, Coastal and Ocean Eng 111: 459-475.

Wang Y-H (2007) Formula for predicting bedload transport in oscillatory sheet flows. Coastal Eng 54: 594-601.

Wang DW, Kaihatu JM, Wang PA (2002) On the analysis of dispersion relation of spatially shoaling waves. Preprints, $7^{\text {th }}$ International Workshop on Wave Hindcasting and Forecasting.

White TE (1989) Using sediment-threshold theories in waves and currents. Proc Int Symp on Sediment Transport Modelling - ASCE, New York, pp 248-253.

Whitehouse RJS, Hardisty J (1988) Experimental assessment of two theories for the effect of bedslope on the threshold of sediment transport. Marine Geol 79: 135-139.

Wiegel RL (1960) A presentation of cnoidal wave theory for practical application. J Fluid Mech 7: $273-286$.

You ZJ, Yin B (2006) A unified criterion for initiation of sediment motion and inception of sheet flow under water waves. Sedimentology 53: 1181-1190. 


\section{APPENDIX 1. LIST OF SYMBOLS}

\section{Main symbols:}

A Water particle displacement (semi- excursion)

$2 A$ Orbital diameter (full water particle excursion)

$a \quad$ Coefficient used in solution of Cokelet's theory

$b \quad$ Coefficient used in solution of Cokelet's theory

C Fully developed wave celerity

D Median sieve-size grain diameter

$D W L \quad$ Displaced water level

d Water depth with reference to $S W L$

E Total wave energy

$f \quad$ Factor used to compute wave profile

$G \quad$ Factor used to compute wave profile

$g \quad$ Acceleration due to gravity

$H \quad$ Significant, energy-based, fully developed wave height

$h \quad$ Exponent used to compute wave profile

I Factor used to compute wave profile

$J \quad$ Factor used to compute critical boundary velocity

$k \quad$ Wave number

L Fully developed wavelength

$M C D$ Median crest diameter

MTD Median trough diameter

$P \quad$ Gauge pressure

$s^{*} \quad$ Scaled dimensionless immersed sediment weight

SWL Still water level

$T_{\mathrm{w}} \quad$ Fully developed wave period

$T_{R} \quad$ Factor used to compute critical boundary velocity

$t \quad$ Time lapse

$U \quad$ Water particle velocity

$\mathrm{U}_{\mathrm{R}} \quad$ Ursell number 
$X \quad$ Distance of breaker from $S W L$ shoreline

$x \quad$ Distance from wave crest in direction of wave propagation

y Distance from bottom

$z \quad$ Distance below $S W L$

$\alpha \quad$ Bottom slope (degrees)

$\delta \quad$ Boundary layer thickness

$\eta \quad$ Water surface elevation with respect to $S W L$

$\theta \quad$ Wave phase

$\Omega \quad$ Latitude

$\omega \quad$ Radian frequency

$v \quad$ Water kinematic viscosity

$\mu \quad$ Water dynamic viscosity

$\rho \quad$ Water density

\section{Subscripts}

$a \quad$ Wind (referring to velocity at $10 \mathrm{~m}$ above $S W L$ )

$b \quad$ Condition at breaking depth

c Condition under wave crest

$\mathrm{cr} \quad$ Condition at threshold of sediment motion

$d \quad$ Dimensionless value

$g \quad$ Wave generating depth

$h \quad$ Horizontal direction

$o \quad$ Condition in deep water

$p \quad$ Provisional condition

$S \quad$ Sediment (with reference to density)

$t \quad$ Condition under wave trough

$v \quad$ Vertical direction

w Condition in any water depth

$z \quad$ Condition at distance $z$ below $S W L$

$\alpha \quad$ Conditions over sloping bottom

$\delta \quad$ Condition at top of boundary layer 